\title{
Usando técnicas de aprendizagem colaborativa para incentivar o ensino-aprendizagem de programação entre as alunas de cursos de Computação
}

\author{
Géssica M. da S. Alves ${ }^{1}$, Jailma J. da Silva ${ }^{1}$, Rebeca de Q. Dantas ${ }^{1}$, Vanessa F. \\ Dantas $^{1}$, Renata V. de Figueiredo ${ }^{1}$, Gabriela C. M. de Souza ${ }^{1}$ \\ ${ }^{1}$ Universidade Federal da Paraíba (UFPB) \\ \{gessica.monique,jailma.januario, rebeca.queiroz, vanessa, renata, \\ gabriela\} @dcx.ufpb.br
}

\begin{abstract}
Statistically, the entry and permanence of women in technology courses still have low indicators. The Programming subjects are still seen as those with the highest rates of failure, and identified as one of the reasons for women dropping out. This article aims to report an initiative of using Dojo programming technique to empower and encourage women students of Computer Science and Information Systems courses at Federal University of Paraiba (UFPB) to build solutions collaboratively.
\end{abstract}

Resumo. Estatisticamente, o ingresso e a permanência de mulheres nos cursos da área de tecnologia ainda têm indicadores reduzidos. Dentre as disciplinas com maiores índices de reprovação, estão as de Programação, apontadas como uma das causas da desistência das meninas na área. O presente artigo tem como objetivo relatar uma iniciativa do uso da técnica Dojo de Programação para capacitar e incentivar as discentes dos cursos de Licenciatura em Ciência da Computação e Bacharelado em Sistemas de Informação da Universidade Federal da Paraíba (UFPB) a construir soluções de forma colaborativa.

\section{Introdução}

As mulheres ainda são minoria no ingresso e permanência nos cursos de Computação e Ciências Exatas em geral. As estatísticas mostram que, nas universidades de todo o Brasil, há uma discrepância na procura dos cursos de Computação por mulheres em relação aos homens nesta área (Lima, 2013).

Segundo Lima (2013), a concentração de homens em cursos de Ciência da Computação chega a 79,9\%. Em alguns casos, o cenário local pode ser ainda mais crítico que o nacional. Por exemplo, na UFPB, especificamente no Campus IV, no semestre em andamento existem 248 alunos regularmente matriculados no curso de Licenciatura em Ciência da Computação. Destes, só 41 são do sexo feminino, o que representa pouco mais de $16 \%$ do total. Entre os alunos ingressantes no período anterior, havia apenas uma mulher. Além do ingresso nos cursos de Computação ser menor pelas mulheres, dados mostram que, das mulheres que ingressam nestes cursos, $79 \%$ abandonam a faculdade no primeiro ano (SINDPD/SP, 2015).

Segundo Paula et al (2011), uma das principais causas da evasão está na falta de preparo dos alunos ingressantes nas faculdades. Acostumados com o ensino tradicional, baseado em perguntas e respostas prontas, os alunos têm dificuldade de formular novos 
conceitos e solucionar problemas complexos, especialmente aqueles que envolvem senso crítico e raciocínio apurado. No caso específico das mulheres, além desses aspectos, há ainda questões como inibição por serem minoria nas turmas, falta de identificação com o curso por não conhecerem mulheres de destaque na área, e o fato de muitas vezes não terem sido estimuladas a desenvolver o raciocínio lógico desde a infância.

É importante adotar medidas que possam contribuir para combater a disparidade entre homens e mulheres na Tecnologia da Informação, aproximando as meninas da área de modo que elas se sintam motivadas e capazes de superar desafios.

Sabendo que algumas dissertações e projetos de fim de curso discutem o uso de Dojos como ferramenta de ensino em cursos superiores [Fontes 2011, Cukier 2009, Bravo 2011], o objetivo deste artigo é relatar uma experiência com a aplicação da técnica para incentivar e capacitar as discentes dos cursos de Computação do Campus IV na área de programação.

$\mathrm{Na}$ Seção 2, há uma breve descrição da técnica Dojo e da metodologia empregada neste trabalho. Os dados sobre a realização das sessões de codificação e alguns resultados observados encontram-se na Seção 3. Por fim, a Seção 4 apresenta as considerações finais e perspectivas de trabalhos futuros.

\section{Metodologia}

A literatura define Dojo de Programação como um encontro de programadores visando à solução de um desafio de programação (Bossavit et al. 2011). Entre seus princípios básicos, está a criação de um ambiente não competitivo e propício ao aprendizado contínuo, permitindo que participantes estejam motivados a contribuir. O Dojo é uma atividade dinâmica e que favorece o aprendizado, incluindo e incentivando os alunos a participar do processo de aprendizado de forma colaborativa (Bossavit et al. 2011) e (Sato et al. 2008).

Para que fosse possível a realização de sessões Dojo de Programação junto às discentes dos cursos de Computação da UFPB, Campus IV, foram definidas três etapas importantes: um estudo sobre os diferentes formatos de Dojo e suas diretrizes, uma pesquisa sobre problemas de programação adequados ao nível de conhecimento das discentes, e um planejamento sobre a avaliação da experiência pelas alunas.

\subsection{Estudo sobre a técnica Dojo}

Inicialmente, foi realizado um estudo sobre as diferentes técnicas de Dojo existentes, com o objetivo de escolher aquela que fosse mais adequada para um primeiro contato com as discentes. Segundo Sato et al. (2008), existem três formatos de encontros: Kata, Randori e Kake. Em todos eles, os alunos são incentivados a trabalhar colaborativamente, muitas vezes se revezando entre duplas e entre máquinas, mas existem algumas diferenças no modo de condução das sessões.

O formato escolhido para aplicação foi o Randori, que propõe que, diante de um problema de programação proposto, as alunas se alternem, a cada seis minutos, nos papéis de piloto e co-piloto em uma única máquina, de modo que a plateia possa 
acompanhar a construção do código, opinando e fazendo questionamentos. O objetivo é garantir a interação entre as envolvidas, tornando o ambiente colaborativo.

\subsection{Escolha de problemas de programação}

Para que fossem selecionadas questões adequadas ao nível de conhecimento das alunas, foram feitas buscas em repositórios de questões, como o do juiz online URI (https://www.urionlinejudge.com.br/), e também foram realizadas conversas com os professores da disciplina Linguagem de Programação, ofertada para ambos os cursos de Computação da instituição. A linguagem Java foi escolhida para ser abordada em todas as sessões Dojo, uma vez que ela é objeto de estudo da citada disciplina.

\subsection{Planejamento da avaliação}

Com o objetivo de obter feedback das alunas sobre o uso do Dojo de programação, foi elaborado um formulário online composto por perguntas objetivas (com escala variando entre muito ruim, ruim, regular, bom e muito bom), e discursivas acerca das sessões realizadas. As questões contemplavam aspectos como percepção sobre o tempo estimado e a complexidade dos problemas, clareza das instrutoras na comunicação, e satisfação quanto à participação nas atividades.

\section{Resultados e Discussão}

Foram realizadas duas sessões Dojo, uma no mês de setembro e outra em novembro, com a participação de sete alunas dos cursos de Licenciatura em Ciência da Computação e Bacharelado em Sistemas de Informação. Em ambas as ocasiões, as apresentadoras, que também são alunas dos cursos da instituição, introduziram os problemas a serem resolvidos, e logo em seguida iniciaram a dinâmica da troca de duplas na construção colaborativa da solução.

A primeira sessão foi mais longa, com duração de duas horas, para que as alunas tivessem tempo de se adaptar à técnica e ao trabalho em duplas, uma vez que todas relataram não terem conhecimento algum sobre o Dojo. Já a segunda sessão teve uma participação mais ativa das discentes, que conseguiram resolver o problema proposto em apenas uma hora.

Após as sessões, todas as participantes responderam o questionário de avaliação previamente elaborado, e foi possível obter informações relevantes sobre as percepções delas. Quando questionadas sobre o grau de satisfação em participar da atividade, as respostas se dividiram entre bom $(50 \%)$ e muito bom $(50 \%)$. Quanto à comunicação das apresentadoras durante as sessões, $83,3 \%$ delas consideraram a comunicação muito boa, e $16,7 \%$ julgaram que foi boa. Esses dois indicadores indicam que as alunas aprovaram a técnica, e a forma como foram conduzidas as sessões.

Já em relação à adequação do tempo de cada sessão para os problemas propostos, 66,7\% consideraram que foi regular, e 33,33\% acharam que foi bom. Quando questionadas sobre o grau de dificuldade dos problemas apresentados, as respostas se dividiram entre bom $(16,7 \%)$, regular $(33,3 \%)$, e ruim $(50 \%)$. Esses dois indicadores evidenciam a necessidade de reformulação futura das sessões, de modo que sejam 
escolhidos problemas mais simples e que possam ser resolvidos no tempo proposto confortavelmente.

No campo discursivo do formulário em que eram pedidas sugestões, as participantes afirmaram que é preciso experimentar dinâmicas como as do Dojo, relataram a importância da iniciativa, e destacaram o quanto gostariam que outros problemas do mundo real fossem usados nas próximas sessões, como exercício das habilidades de programação.

\section{Considerações Finais}

Além das dificuldades comumente encontradas para compreender lógica de programação, muitas vezes as mulheres que ingressam em cursos de tecnologia se vêem também inibidas por serem minoria e não se sentem à vontade para fazerem perguntas em sala, o que pode tornar o aprendizado de programação solitário e frustrante.

Com o objetivo de entrosar mais as alunas e incentivá-las na área de programação, este trabalho teve por objetivo utilizar uma técnica diferente de ensinoaprendizado, as sessões Dojo. Embora tenham sido realizadas poucas sessões, e o número de participantes tenha sido pequeno, essa experiência foi fundamental para que a equipe se familiarizasse com a técnica, e pudesse obter um importante feedback para a realização de futuras sessões. Além disso, todas as alunas envolvidas aprovaram a iniciativa, e venceram algumas de suas limitações, aprendendo de forma participativa e colaborativa.

Espera-se que novas sessões Dojo sejam realizadas, envolvendo também alunas de outras disciplinas de programação dos cursos, e que possam ser analisados dados que evidenciem o impacto dessa técnica no desempenho acadêmico das discentes.

\section{Referências}

Bossavit, L., Gaillot, E. and Bache, E. (2011). Coding Dojo Wiki: What Is Coding Dojo. Wiki. http://codingdojo.org/cgi-bin/wiki.pl?WhatIsCodingDojo.

Bravo, M. (2011). Abordagens para o ensino de práticas de programação extrema. Dissertação de Mestrado, Universidade de São Paulo, São Paulo, SP.

Cukier, D. (2009). Padrões para introduzir novas ideias na indústria de software. Dissertação USP 2009.

Fontes, B. (2011). Coding dojo: novas possibilidades para o ensino de programação. Projeto de Diplomação, Universidade Federal Fluminense, Niterói, RJ.

Lima, M. P (2013) “As mulheres na Ciência da Computação”. Rev. Estud. Fem. vol 21 no.3. Florianópolis.

Paula, L. Q., PIVA JR., D., FREITAS, R. L. A Importância da Leitura e da Abstração do Problema no processo de formação do raciocínio lógico-abstrato em alunos de Computação. Anais do XVII Workshop sobre Educação em Informática. São Leopoldo - RS, Brasil, 2009. 
Sato, D. T., Corbucci, H. and Bravo, M. (2008). Coding Dojo: an environment for learning and sharing agile practices. In Proceedings of the Agile 2008. . IEEE Computer Society. http://dx.doi.org/10.1109/Agile.2008.11.

SINDPD/SP (2015). Número de contratações supera demissões no setor de TI no $1^{\circ}$ semestre.

$<$ http://convergenciadigital.uol.com.br/cgi/cgilua.exe/sys/start.htm?infoid=40683>. Acessado em 21/03/2017. 